\section{Fibroelastoma papilar con origen en la válvula pulmonar: tratamiento quirúrgico de un tumor asintomático}

\section{Papillary fibroelastoma originating from pulmonary valve: Surgical treatment asymptomatic tumor}

La incidencia de los tumores cardíacos se estima en algunas series del 0.001 al $0.28 \%$ y en otras hasta en un $0.33 \%{ }^{1}$. El $90 \%$ de los tumores cardíacos son benignos, siendo el mixoma el más común de estos $(50 \%)^{2}$.

El fibroelastoma papilar, también denominado papiloma fibroelástico, es un tumor benigno poco común el cual se puede observar en las válvulas cardíacas ${ }^{3,4}$ o en algunas ocasiones en el endocardio ventricular. En orden de frecuencia, ocupa el tercer lugar de los tumores benignos cardíacos primarios, después del mixoma y el lipoma ${ }^{4,5}$. Se observa con más frecuencia en pacientes mayores de 50 años, aunque puede presentarse a cualquier edad. Hasta hace poco era un hallazgo incidental en la cirugía o en el examen posmortem. Hoy en día, se descubren cada vez más fibroelastomas por imágenes ecocardiográficas ${ }^{2-4}$. Estos tumores se fijan al endotelio por un pedículo corto. Tienen predilección por la válvula aórtica ${ }^{6}$ donde pueden ser causantes de angina, infarto o muerte súbita debido a embolización u oclusión ostial coronaria causada por el tumor velloso. También se han reportado émbolos cerebrales y oculares ${ }^{2-4}$. Otros sitios donde pueden localizarse son la válvula mitral ${ }^{6}$, tricúspide y el endocardio ventricular ${ }^{7}$. Con menos frecuencia en la válvula pulmonar ${ }^{1,8}$.

La escisión quirúrgica está indicada de forma temprana debido a su potencial embolización cerebral y coronaria, incluso para fibroelastomas papilares pequeños ${ }^{2,4,6,8}$. Los fibroelastomas papilares pueden parecer vegetaciones $y$ mimetizar la imagen de una endocarditis bacteriana.

El presente caso se trata de una mujer de 46 años, hipertensa, en tratamiento por dislipidemia. Asintomática cardiovascular. Durante una revisión rutinaria se evidencia un hallazgo radiográfico de cardiomegalia grado । por lo que se realiza ecocardiograma, describiendo tumoración en el tracto de salida del ventrículo derecho, circular de $27 \times 19 \mathrm{~mm}$ de diámetro (fig. 1), PSAP de $32 \mathrm{mmHg}$, FE del ventrículo izquierdo del $79 \%$. Válvulas mitral, tricúspide y pulmonar normofuncionantes. Se decide internamiento para completar estudios y tratamiento quirúrgico.

Sin signos evidentes a la exploración física por sistemas. Laboratorios sin alteraciones. Electrocardiograma: FC $58 \mathrm{lpm}, \mathrm{P} 100 \mathrm{~ms}, \mathrm{PR} 180 \mathrm{~ms}, \mathrm{aQRS}+30$ sin datos de crecimiento de cavidades. No se observan datos de isquemia o necrosis. Recibió tratamiento quirúrgico con diagnóstico de tumoración en tracto de salida del ventrículo derecho.

Técnica. Abordaje anterior vía esternotomía media, derivación cardiopulmonar normal y parada cardíaca. Por vía transpulmonar se reseca lesión tumoral adherida a válvula pulmonar y eventrada hacia ventrículo derecho con diámetro aproximado de $2 \mathrm{~cm}$ (fig. $2 \mathrm{~A}$ y B). Se preserva válvula pulmonar nativa. La evolución postoperatoria es favorable. Egresa de la terapia intensiva a las $48 \mathrm{~h}$ posteriores a la cirugía y del instituto, asintomática cardiovascular, a los 7 días.

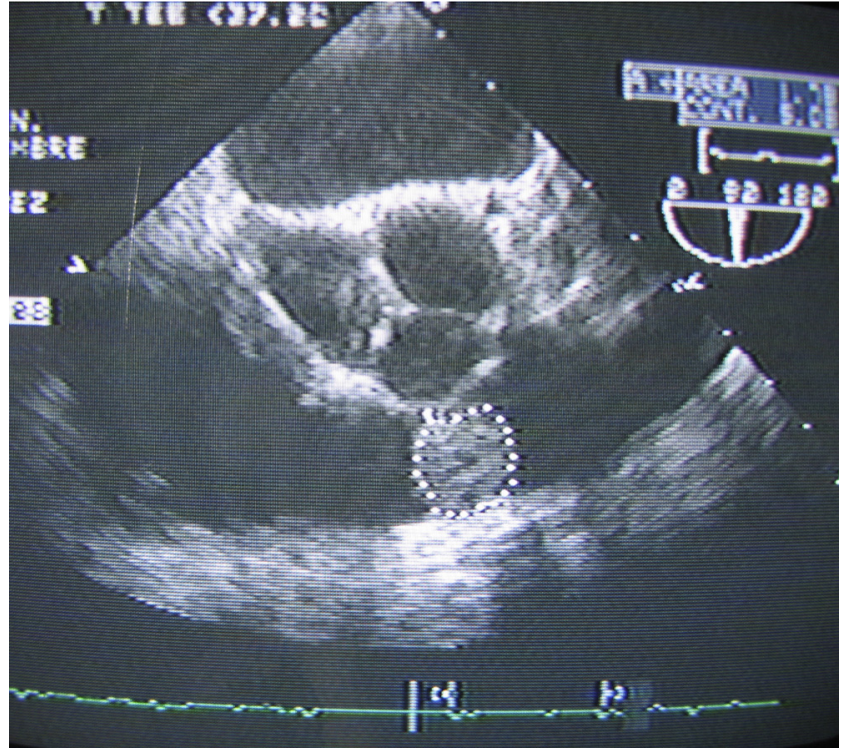

Figura 1 Ecocardiograma. Se aprecia una masa de $2 \mathrm{~cm}$ de diámetro en tracto de salida del ventrículo derecho, además de observarse la válvula aórtica y la arteria pulmonar.

Informe histopatológico. Fibroelastoma papilar, cuyo cuerpo está compuesto por fibras de colágenas, fibras elásticas y músculo liso, todo esto recubierto de endotelio (fig. 2C).

Los tumores del corazón son una entidad de escasa presentación en la práctica médica ${ }^{9}$. Originan una amplia variedad de manifestaciones clínicas y alteraciones hemodinámicas y pueden simular cualquier cardiopatía dependiendo de su localización.

La etiopatogenia del fibroelastoma papilar es desconocida. Existen varias teorías: algunas muestran la posibilidad de que se trate de un tumor inducido por virus, debido a la presencia de células dendríticas y citomegalovirus que se han encontrado en estudios histológicos e inmunohistoquímicos. Otras evocan el concepto de una forma crónica de endocarditis viral ${ }^{8}$. En otros casos, la asociación de enfermedad cardíaca congénita y la edad temprana en el momento de la presentación del fibroelastoma papilar apoyan la hipótesis de una base congénita, sin embargo la mayoría de los fibroelastomas papilares parecen ser de origen adquirido ${ }^{10}$, siendo la mayoría de origen neoplásico o trombótico. En estos casos, el flujo turbulento y los acontecimientos mecánicos traumáticos podrían estimular las células endoteliales a causar hiperplasia de las mismas, justificando así la degeneración estromal del tejido ${ }^{1,4,6,11}$.

Histológicamente, el tumor está recubierto por endotelio, mientras que la parte interior está formada por una capa de mucopolisacáridos con un estroma principalmente consistente de colágena, fibras de músculo lisas y fibras elásticas en cantidades variables ${ }^{2,3,5}$. El fibroelastoma papilar cardíaco es un tumor benigno, pero puede tener una evolución fatal, por las complicaciones a las que puede dar origen, incluso amenazando la vida del paciente. Por ello, la escisión quirúrgica es justificada una vez realizado el diagnóstico, independientemente de los síntomas, localización o dimensiones de la masa ${ }^{8}$. 

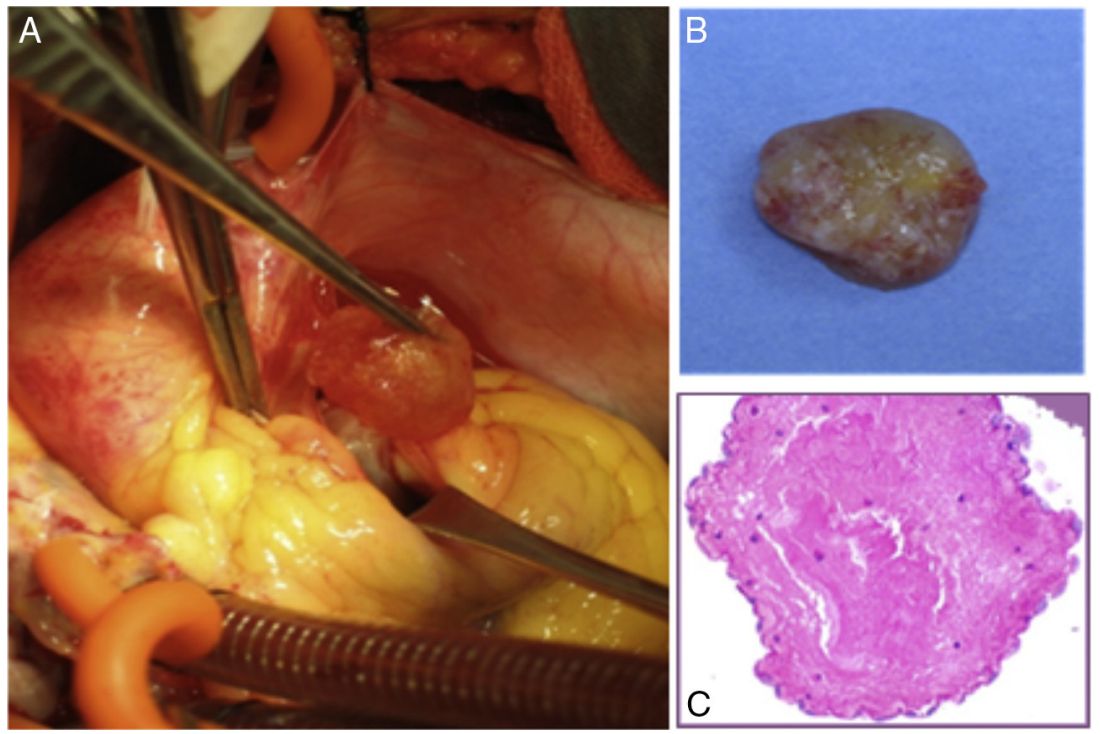

Figura 2 A) Exposición de tumor pediculado en tracto de salida VD, válvula pulmonar (B). Pieza quirúrgica (C). Corte histológico teñido con ácido peryódico de Schiff con aumento de 10x. El interior de estos tumores es rico en mucopolisacáridos, puede contener fibras colágenas, músculo liso y fibras elásticas en cantidades variables y está recubierto de endotelio.

El tratamiento quirúrgico es realizado con derivación cardiopulmonar con o sin parada cardíaca. La resección es similar a la llevada a cabo con otros tumores. Sin embargo debe prestarse especial atención a la manipulación de la masa debido a su friabilidad y alto riesgo de embolización ${ }^{1,3}$.

\section{Financiación}

No se recibió patrocinio de ningún tipo para llevar a cabo este estudio/artículo.

\section{Conflicto de intereses}

Los autores declaran no tener ningún conflicto de intereses.

\section{Bibliografía}

1. Saad S, Galvis O, Bshara W, et al. Pulmonary Valve papillary fibroelastoma. A case report and review of the literature. Arch Pathol Lab Med. 2001;125:933-4.

2. Neerukonda K, Jantz D, Vijay K, et al. Pulmonary embolization of papillary fibroelastoma. Arising from the tricuspid valve. Tex Heart Inst J. 1991;18:132-5.

3. Sun J, Asher C, Yang X, et al. Clinical and echocardiographic characteristics of papillary fibroelastomas: A retrospective and prospective study in 162 patients. Circulation. 2001;5:2687-93.

4. Tanaka H, Narisawa T, Mori T, et al. Double primary left ventricular and aortic valve papillary fibroelastoma. Circulation. 2004;68:504-6.

5. Al-Mohammad A, Pambakian H, Young C. Fibroelastoma: Case report and review of the literature. Heart. 1998;79:301-4.

6. Borsani P, Mariscalco G, Blanzola C, et al. Asymptomatic cardiac papillary fibroelastoma: Diagnostic assessment and therapy. J Card Surg. 2006;21:77-80.
7. Abad C. Tumores cardiacos (I). Generalidades. Tumores primitivos benignos. Rev Esp Cardiol. 1998;51:10-20.

8. Kovacević M, Simić $O$, Matana A, et al. Pulmonary valve papillary fibroelastoma. A case report. Tumori. 2005;91:364-5.

9. Hernández-Bringas 0 , Ortiz-Hidalgo C. Características histopatológicas e inmunohistoquímicas de los mixomas cardíacos. Arch Cardiol Mex. 2013;83:199-208.

10. Caballero J, Calle G, Arana R, et al. Fibroelastoma papilar cardiaco. Diferentes formas de presentación clínica. Rev Esp Cardiol. 1997;50:815-7.

11. Grandmougin D, Fayad G, Moukassa D, et al. Cardiac valve papillary fibroelastomas: Clinical, histological and immunohistochemical studies and a physiopathogenic hypothesis. J Heart Valve Dis. 2000;9:832-41.

James Parada-Lorenzana ${ }^{\mathrm{a}, *}$, Javier López ${ }^{\mathrm{a}}$, Elizabeth Aguilar ${ }^{\mathrm{a}}$, Valentín Herrera ${ }^{\mathrm{b}}$, Rodolfo Barragán ${ }^{\mathrm{c}}$ y Lizbeth Gómez ${ }^{\mathrm{d}}$

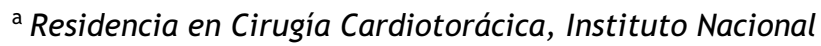
de Cardiología Ignacio Chávez, México DF, México

${ }^{\mathrm{b}}$ Departamento de Cirugía Cardiotorácica, Instituto Nacional de Cardiología Ignacio Chávez, México DF, México ' Subdirección Médico-Quirúrgica, Instituto Nacional de Cardiología Ignacio Chávez, México DF, México d Residencia en Cirugía de Malformaciones Congénitas Cardíacas, Instituto Nacional de Cardiología Ignacio Chávez, México DF, México

* Autor para correspondencia: Juan Badiano n. ${ }^{\circ}$ 1. Sección XVI, Delegación Tlalpan. CP 14080. México DF, México. Teléfono: 5542159604.

Correo electrónico: reesejamessv@yahoo.com (J. Parada-Lorenzana).

http://dx.doi.org/10.1016/j.acmx.2013.10.009 